\title{
Development of novel melt-compounded starch-grafted polypropylene/polypropylene-grafted maleic anhydride/organoclay ternary hybrids
}

\author{
R. Tessier ${ }^{1,2}$, E. Lafranche ${ }^{1,2^{*}}$, P. Krawczak ${ }^{1,2}$ \\ ${ }^{1}$ Ecole Nationale Supérieure des Mines de Douai, Department of Polymers and Composites Technology and Mechanical \\ Engineering, 941 rue Charles Bourseul, CS 10838, F 59508 Douai, France \\ ${ }^{2}$ Université Lille Nord de France, 59000 Lille, France
}

Received 18 April 2012; accepted in revised form 25 June 2012

\begin{abstract}
Starch-grafted polypropylene (PP-g-starch)/organoclay nanocomposites were melt-compounded using a corotating twin-screw extruder. Homopolymer or copolymer-based polypropylene-grafted maleic anhydrides (PP-g-MA) with different molecular weights and different maleic anhydride (MA) grafting levels were added at different weight contents as compatibilizer. Two organo-modified montmorillonites were used, the first one containing polar functional groups (Cloisite ${ }^{\circledR}$ 30B) having affinity to the starch phase, and the other one containing non polar-groups (Cloisite $\left.{ }^{\circledR} 20 \mathrm{~A}\right)$ having affinity to the polypropylene phase of the polymer matrix. Whatever the MA grafting level and the molecular weight and content of PP-g-MA, no significant immiscibility of PP-g-starch/PP-g-MA blends is evidenced. Regarding clay dispersion, adding a low content of ethylene-propylene copolymer-based PP-g-MA compatibilizer having a high MA-grafting level, and a polar organoclay $\left(\right.$ Cloisite $\left.{ }^{\circledR} 30 \mathrm{~B}\right)$ is the most desirable formulation to optimize clay intercalation and exfoliation in PP-g-starch. Nevertheless, regarding the reinforcement effect, whatever the PP-g-MA compatibilizer, the addition of non polar organoclay (Cloisite ${ }^{\circledR} 20 \mathrm{~A}$ ) is preferably recommended to reach higher tensile properties (modulus, yield stress, strength) without significant loss of ductility.
\end{abstract}

Keywords: nanocomposites, polymer blends, starch, clay, mechanical properties

\section{Introduction}

Ever-growing concern related to sustainability and ecology has been the key driving force for developing bio-based plastics. In single-use packaging applications, biodegradability is an advantage and poor mechanical properties remain acceptable. Automotive applications are however much more challenging as durable bioplastics are expected to meet very demanding requirements, such as high thermo-mechanical performance (strength and rigidity) often coupled with dimensional accuracy and stability [1]. The most widely spread bioplastics, namely biopolyamide 11, poly(lactic acid) and ther- moplastic starch, are unfortunately often either too expensive or too sensitive to ageing and humidity, and are not rigid and resistant enough to be used to manufacture automotive plastic parts. The issue is therefore to reinforce bio-based plastics whose properties are not high enough to replace the fully petroleum-based polymers. This may be achieved for example by addition of cheap micro- or nano-scaled fillers (particles or fibres), so as to develop costeffective composite or nanocomposite materials reaching the expected level of performance [1].

Considering this constraining application field, raw material producers have developed hybrid (bipha-

\footnotetext{
${ }^{*}$ Corresponding author, e-mail: eric.lafranche@mines-douai.fr
} (c) BME-PT 
sic) polymers where a bio-based matrix is associated with a more conventional polyolefin matrix (polyethylene, polypropylene). In particular starchgrafted polypropylene may provide a suitable alternative solution to supply automotive industry with a durable 'green' thermoplastic [2]. Nevertheless, reaching the desired level of mechanical performance still requires further reinforcement by addition of nanofillers for instance, as it was done with the development of bio-based nanocomposites dedicated to packaging applications [3]. In that case, layered silicate nanoplatelets are commonly used and among the different types of clay, montmorillonite (MMT) is the most used nanofiller because of its low cost, natural abundance and high aspect ratio.

Biphasic thermoplastic matrices such as Gaïalene ${ }^{\circledR}$ (Roquette, France [2]) made of polypropylene (PP) grafted with starch at a 48/52 weight ratio form a complex polymer system with hydrophilic and hydrophobic phases in which clay has to be dispersed and exfoliated. Thermoplastic starch is hydrophilic. In that case, a better dispersion and exfoliation is usually obtained with native clay $\left(\mathrm{Na}^{+}-\mathrm{MMT}\right.$, unmodified sodium montmorillonite), which is naturally hydrophilic. Polar interactions are created between the silicate lamella and the hydroxyl groups of the starch [4-6].

The dispersion, intercalation and exfoliation of clay, and especially montmorillonite, in PP have also been widely investigated [7-17]. The exfoliation of clay platelets is an uphill task, particularly in non-polar hydrophobic polymers like PP because of the unfavourable enthalpic interaction with the highly hydrophilic clay, which prohibits the diffusion of polymer molecules into the intergallery space. Even if attempts have been made to use pristine (unmodified) clay [7], modification of clay with organic cations (by cationic exchange with the sodium cations of the mineral) and addition of compatibilizers such as maleic anhydride (MA) are common solutions used to improve the interaction between PP and clay nanoplatelets. Besides, proper choice of processing conditions may further improve clay dispersion [8]. The organic cations used for clay modification are usually alkyl ammonium cations with different chemical structures depending on the considered polymer matrix. Generally apolar alkyl ammonium cations are used in the case of apolar polymers such as PP $[10,11]$. It is now well admitted that clay dispersion in PP and interfacial adhesion are better with a non-polar clay modifier such as the one used in Cloisite ${ }^{\circledR} 20 \mathrm{~A}$ (Southern Clay Product) than with pristine (i.e. native) clay or polar clay modifier such as that used in Cloisite ${ }^{\circledR} 30 \mathrm{~B}$ (Southern Clay Product) [12]. Similarly, as for carbon nanotubes [18], it is well known that a better clay dispersion and exfoliation is achieved when PP-g-MA compatibilizers are used. Some authors [11-16] investigated the compatibilizer influence on the clay exfoliation. A high maleic anhydride grafting level enables a better molecular insertion between the lamella, but a molecular weight decrease of the polypropylene may be expected due to molecular chain breakage $[10,12,17]$. A higher compatibilizer molecular weight increases the melt viscosity [15], which may be favourable to break the clay tactoids, but may also hinder the diffusion mechanism of the polymer chain in clays interlayer space at low temperature. In practice, a balance between compatibilizer molecular weight and maleic anhydride grafting level is necessary to optimize clay exfoliation (even if full exfoliation cannot be obtained in PP matrices due to the huge polarity difference between the matrix and the clay) and thus mechanical properties $[11,12,15]$.

Furthermore, some authors highlighted the interest of using solid nanoparticles (clays among others [19-21]) to improve the properties of polymer blends, the nanofiller playing the role of both structural reinforcement and compatibilizer. In particular in the case of clays, when the platelets are organomodified, the nature of the surfactant can influence the location of clay platelets in immiscible polymer blends, affect the coalescence behaviour and, effectively, reduce the size of the dispersed phase, decrease the interfacial tension and improve the adhesion between the phases [22, 23]. However, whereas it is commonly admitted that organoclays may act as compatibilizers in the case of immiscible polymer blends, the exact mechanism involved is still unclear. Yousfi et al. [24] have recently shown that the key factor for organoclay compatibilization efficiency is the surfactant (organo-modifier) itself and not solely the presence of clay platelets.

In that context, the general objective of the present research program is to develop, based on a newly marketed biphasic starch-grafted polypropylene 
matrix, compatibilized starch-grafted polypropylene/organoclay nanocomposites by melt-compounding so as to up-grade its mechanical performance. In particular, this paper aims at understanding the influence of both the PP-g-MA compatibilizer (weight content and maleic anhydride grafting level) and the organoclay modifier on the clay dispersion in the complex biphasic starch-grafted polypropylene matrix. The miscibility was evaluated by rheology and microscopy. Then, the intercalation and/or exfoliation were assessed by rheological analysis coupled to morphological observations. Finally, the resulting tensile properties were characterized.

\section{Experimental}

\subsection{Materials}

The material studied was a $52 \mathrm{wt} \%$ plant-based starch-grafted polypropylene (Gaïalene ${ }^{\circledR}$ 906PJ, Roquette, France) with an MFR of $30 \mathrm{~g} / 10 \mathrm{~min}$ $\left(190^{\circ} \mathrm{C} / 10 \mathrm{~kg}\right)$, further named PP-g-starch. Three commercial maleated polypropylenes (Polypropylene-grafted maleic anhydride, PP-g-MA) were used: two homopolymers with graft efficiency of $0.5 \mathrm{wt} \%$ (Fusabond ${ }^{\circledR}$ P613, Dupont, Switzerland - further named PP-g-MA1) and $1 \mathrm{wt} \%\left(\mathrm{Orevac}^{\circledR} \mathrm{CA} 100\right.$, Arkema, France - further named PP-g-MA2), and one ethylene-propylene copolymer with graft effi- ciency of $1.4 \mathrm{wt} \%$ (Fusabond $^{\circledR} \mathrm{P} 353$, Dupont, Switzerland - further named PP-g-MA3), the ethylene content in the copolymer being $52 \mathrm{wt} \%$. The clays were sodium montmorillonite modified with quaternary ammonium salt, one polar modified nanoclay (Cloisite ${ }^{\circledR} 30 B$, Southern Clay Products Co., USA - further named C30B) and one non-polar modified nanoclay (Cloisite ${ }^{\circledR} 20 A$, Southern Clay Products Co., USA - further named C20A). The main characteristics of the materials are summarized in Table 1.

\subsection{Compounding conditions}

The PP-g-starch/PP-g-MA and PP-g-starch/PP-g$\mathrm{MA} /$ organoclay compounds were obtained by meltblending in a twin-screw extruder (Haake Polylab, Thermo Scientific, Germany) equipped with a $16 \mathrm{~mm}$ screw diameter and a length/diameter ratio $L / D$ of $29: 1$, operating at $160-180^{\circ} \mathrm{C}$ and $200 \mathrm{rpm}$. Polymers were first mixed before introduction in the extruder. The clays were then introduced in the polymer melt just before a screw mixing zone (Figure 1). Raw materials were dried at $80^{\circ} \mathrm{C}$ during 4 hours in order to get a relative humidity of $8000 \mathrm{ppm}$. The composition of the compounds is detailed in Table 2.

Table 1. Main characteristics of materials used

\begin{tabular}{|c|c|c|c|c|}
\hline Polymer material & $\begin{array}{c}\left.\text { Gaialene }^{(}\right) \\
\text {906PJ } \\
\text { (PP-g-starch) }\end{array}$ & $\begin{array}{l}\text { Fusabond }^{\mathbb{R}} \\
\text { P613 } \\
\text { (PP-g-MA1) }\end{array}$ & $\begin{array}{c}\text { Orevac }^{(B)} \\
\text { CA100 } \\
\text { (PP-g-MA2) }\end{array}$ & $\begin{array}{l}\text { Fusabond }^{\mathbb{R}} \\
\text { P353 } \\
\text { (PP-g-MA3) }\end{array}$ \\
\hline Structure & Starch-grafted & Homopolymer & Homopolymer & $\begin{array}{c}\mathrm{PE} / \mathrm{PP}(52 / 48) \\
\text { copolymer }\end{array}$ \\
\hline $\operatorname{MFR}\left(190^{\circ} \mathrm{C} ; 2.16 \mathrm{~kg}\right)[\mathrm{g} / 10 \mathrm{~min}]$ & $30(10 \mathrm{~kg})$ & 120 & $10(0.325 \mathrm{~kg})$ & 470 \\
\hline Melting point $\left[{ }^{\circ} \mathrm{C}\right]$ & 157 & 162 & 167 & 135 \\
\hline Crystallization point $\left[{ }^{\circ} \mathrm{C}\right]$ & 110 & 108 & 107 & 93 \\
\hline$M_{\mathrm{w}}\left[\mathrm{g} \cdot \mathrm{mol}^{-1}\right]$ & - & 95000 & 89000 & 88700 \\
\hline Density & 1.12 & 0.903 & 0.909 & 0.904 \\
\hline Young's Modulus [MPa] & 420 & 1170 & 1050 & 700 \\
\hline Grafting level [wt $\%]$ & 52 & 0.5 & 1 & 1.4 \\
\hline Organoclay & \multicolumn{2}{|c|}{ Cloisite $^{\mathbb{B}}$ 30B (C30B) } & \multicolumn{2}{|c|}{ Cloisite $^{\circledR} 20 \mathrm{~A}(\mathrm{C20A})$} \\
\hline Organic modifier & \multicolumn{2}{|c|}{$\begin{array}{l}\text { Methyl, tallow, bis-2-hydroxyethyl, quaternary } \\
\text { ammonium chloride, where HT is hydrogenated } \\
\text { tallow ( } 65 \% \mathrm{C} 18,30 \% \mathrm{C} 16,5 \% \mathrm{C} 14) \text {; Anion: } \\
\text { Chloride }\end{array}$} & \multicolumn{2}{|c|}{$\begin{array}{l}\text { Dimethyl, deshydrogenated tallow, quaternary } \\
\text { ammonium chloride, where HT is hydrogenated } \\
\text { tallow (65\% C18, 30\% C16, 5\% C14); Anion: } \\
\text { Chloride }\end{array}$} \\
\hline Structure of organic modifier & \multicolumn{2}{|c|}{$\begin{array}{c}\mathrm{CH}_{2} \mathrm{CH}_{2} \mathrm{OH} \\
\mid \\
\mathrm{CH}_{3}-\mathrm{N}^{+}-\mathrm{T} \\
\mid \\
\mathrm{CH}_{2} \mathrm{CH}_{2} \mathrm{OH}\end{array}$} & \multicolumn{2}{|c|}{$\begin{array}{c}\mathrm{CH}_{3} \\
\mid \\
3^{-}-\mathrm{N}^{+}-\mathrm{HT} \\
\mid \\
\mathrm{HT}\end{array}$} \\
\hline Modifier concentration $[\mathrm{meq} / 100 \mathrm{~g}]$ & \multicolumn{2}{|c|}{90} & \multicolumn{2}{|c|}{95} \\
\hline X-ray $d_{001}[\mathrm{~nm}]$ & \multicolumn{2}{|c|}{1.85} & \multicolumn{2}{|c|}{2.42} \\
\hline$\%$ loss on ignition & \multicolumn{2}{|c|}{30} & \multicolumn{2}{|c|}{38} \\
\hline
\end{tabular}




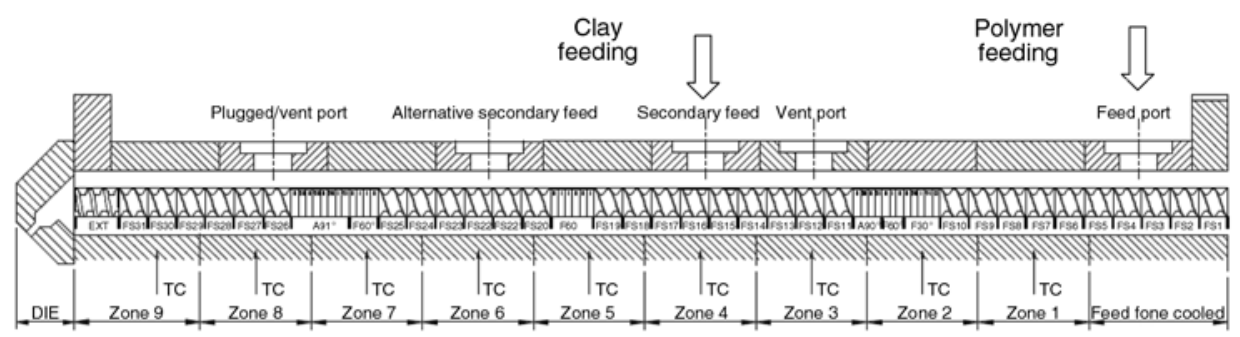

Figure 1. Screw profile of the extruder

Table 2. Sample designation and composition

\begin{tabular}{|l|c|c|c|}
\hline \multicolumn{1}{|c|}{ Sample designation } & $\begin{array}{c}\text { PP-g-starch } \\
\text { wt\% content }\end{array}$ & $\begin{array}{c}\text { PP-g-MA } \\
\text { wt\% content }\end{array}$ & $\begin{array}{c}\text { Neat clay }^{*} \\
\text { wt }_{\text {* content }}\end{array}$ \\
\hline 5PP-g-MA1 (or PP-g-MA2, PP-g-MA3) & 95 & 5 & \\
\hline 10PP-g-MA1 (or PP-g-MA2, PP-g-MA3) & 90 & 10 & \\
\hline 15PP-g-MA1 (or PP-g-MA2, PP-g-MA3) & 85 & 15 & 3.5 \\
\hline 20PP-g-MA1 (or PP-g-MA2, PP-g-MA3) & 80 & 20 & 3.5 \\
\hline 5PP-g-MA2 C30B (or C20A) & 95 & 5 & \\
\hline 20PP-g-MA2 C30B (or C20A) & 80 & 20 & \\
\hline
\end{tabular}

${ }^{*}$ Neat mineral $\mathrm{wt} \%$ content, determined from ignition loss tests to eliminate the surfactant weight fraction of organoclay (corresponds to $5 \mathrm{wt} \%$ Cloisite $^{\circledR}$ organoclay)

The shear rate $\dot{\gamma}$ imposed to the blends during compounding was estimated using an extrusion software package (Ludovic ${ }^{\circledR}$, Sciences Computers Consultants, France). The computed value is $120 \mathrm{~s}^{-1}$.

\subsection{Moulding conditions}

Dumbbell test specimens (ISO 1A) were moulded on an $800 \mathrm{kN}$ clamping force injection-moulding machine (80-160E, Krauss Maffei, Germany). The moulding conditions are summarized in Table 3.

Table 3. Moulding conditions

\begin{tabular}{|l|c|}
\hline \multicolumn{1}{|c|}{ Processing parameters } & Set up value \\
\hline Mould temperature $\left[{ }^{\circ} \mathrm{C}\right]$ & 40 \\
\hline Melt temperature $\left[{ }^{\circ} \mathrm{C}\right]$ & 180 \\
\hline Volume flow rate $\left[\mathrm{cm}^{3} \cdot \mathrm{s}^{-1}\right]$ & 46 \\
\hline Holding pressure $[\mathrm{bar}]$ & 800 \\
\hline Back pressure $[\mathrm{bar}]$ & 20 \\
\hline Screw rotation speed $\left[\mathrm{cm} \cdot \mathrm{s}^{-1}\right]$ & 8.8 \\
\hline
\end{tabular}

\subsection{Mechanical testing}

Tensile tests were performed on a tensile machine (Model 1185, Instron, USA) using an extensometer for strain measurement. Tests were conducted on five samples according to ISO 527 standard at $20 \mathrm{~mm} \cdot \mathrm{min}^{-1}$ crosshead speed for the yield and ultimate properties measurement and at $1 \mathrm{~mm} \cdot \mathrm{min}^{-1}$ for Young's modulus measurement. Samples were stored during 2 days at $23^{\circ} \mathrm{C}$ and $50 \%$ relative humidity before testing.

\subsection{Rheological characterisation}

Oscillatory shear rheological analysis was carried out at 170,180 or $200^{\circ} \mathrm{C}$ under air atmosphere on compression-moulded circular samples $(40 \mathrm{~mm}$ diameter, $2 \mathrm{~mm}$ thick) on a rotational rheometer (ARES, Rheometric Scientific, USA) with parallel plates. Linear domains of the materials were identified from strain sweeps and a common strain of $1 \%$ was then selected for the different samples whatever the testing temperature. Frequency sweeps were run from 0.1 to $100 \mathrm{rad} \cdot \mathrm{s}^{-1}$ in order to record the storage (elastic) modulus $G^{\prime}$ and the complex viscosity $\eta^{*}$.

\subsection{Structural characterisation}

X-ray diffraction (XRD) characterisation of the structure was carried out on clay powder or disks of $50 \mathrm{~mm}$ diameter and $2.3 \mathrm{~mm}$ thickness compression-moulded in a press (Dolouets 383, France; compression pressure of $10 \mathrm{MPa}$ for $1 \mathrm{~min}$ and temperature of $180^{\circ} \mathrm{C}$ ). Wide-angle $\mathrm{X}$-ray scattering experiments were carried out at room temperature in reflection mode. XRD curves were recorded on a diffractometer (D5000, Siemens, Germany) operating at $40 \mathrm{kV}$ and $30 \mathrm{~mA}$ with a beam consisting of CoK $\alpha$ radiation $(\lambda=1.78897 \AA)$. Data were collected in the $2 \theta$ region $2-10^{\circ}$ with a step size of $0.04^{\circ}$ and a counting time of 30 seconds per step. The basal spacing of the organically modified layered silicate (organo-clay) before and after interca- 
lation was estimated from the position of $\left(d_{001}\right)$ peak in the XRD diffractogram according to the Bragg equation $(n \lambda=2 d \cdot \sin \theta)$ where $d$ is the spacing between silica layers of the clay (also called interlayer spacing), $\lambda$ the wave length of X-ray, $\theta$ the reflection angle of $\mathrm{X}$-ray on the silica layer, and $\mathrm{n}$ is a whole number which represents the order of diffraction, taken 1 in our calculations.

Morphological analysis was performed on cryofractured surfaces of injection-moulded samples. A thin layer of gold was sputter deposited onto the sample. Imaging of the samples was carried out under high vacuum with a Scanning Electron Microscope (S-4300SE/N, Hitachi, Japan) operating at $10 \mathrm{kV}$.

Specimens for Transmission Electron Microscopy (TEM) were cut from bulk samples using a microtome (Ultracut UTC and EM FCS, Leica, Germany). Ultra-thin sections were cut using a diamond knife and collected on a 300 mesh copper grid. TEM images were obtained using a TEM instrument (CM20, Philips, The Netherlands) with a $200 \mathrm{kV}$ acceleration voltage. Experiments were carried out at PSA research centre (PSA Peugeot Citroen, France).

\subsection{Interfacial tensions characterisation}

Surface energies (sometimes also called surface tensions as polymers may be liquid-like) of the blended polymers were measured by the sessile drop method using a goniometer (Digidrop, GBX, France). Experiments, consisting in measuring the contact angle of a liquid droplet on a solid substrate, were performed at ISPA (Institut Supérieur de Plasturgie d'Alençon, France). The measurements were carried out at room temperature in static mode under nitrogen atmosphere. The probe liquids were HPLC grade water (surface tension $\sigma=72.8 \mathrm{~mJ} \cdot \mathrm{m}^{-2}$ with polar component $\sigma^{\mathrm{p}}=51.0 \mathrm{~mJ} \cdot \mathrm{m}^{-2}$ and dispersive component $\left.\sigma^{\mathrm{d}}=21.8 \mathrm{~mJ} \cdot \mathrm{m}^{-2}\right)$, formamide $(\sigma=$ $58.2 \mathrm{~mJ} \cdot \mathrm{m}^{-2}$ with $\sigma^{\mathrm{p}}=18.7 \mathrm{~mJ} \cdot \mathrm{m}^{-2}$ and $\sigma^{\mathrm{d}}=$ $\left.39.5 \mathrm{~mJ} \cdot \mathrm{m}^{-2}\right)$, and diiodomethane $\left(\sigma=50.8 \mathrm{~mJ} \cdot \mathrm{m}^{-2}\right.$ with $\sigma^{\mathrm{p}}=49.5 \mathrm{~mJ} \cdot \mathrm{m}^{-2}$ and $\left.\sigma^{\mathrm{d}}=1.3 \mathrm{~mJ} \cdot \mathrm{m}^{-2}\right)$.

The polymers surface energies $(\sigma)$ and their polar $\left(\sigma^{p}\right)$ and dispersive $\left(\sigma^{\mathrm{d}}\right)$ components were determined according to Owens-Wendt theory [25]. The corresponding values are reported in Table 4 for the different materials constituting the blends (PP-gstarch being considered as a one and only phase having its own surface energy).
Table 4. Surface energies $\sigma$ and their dispersive $\sigma^{\mathrm{d}}$ and polar $\sigma^{\mathrm{p}}$ components for the different blends constituents

\begin{tabular}{|l|c|c|c|}
\hline \multicolumn{1}{|c|}{ Material } & $\begin{array}{c}\boldsymbol{\sigma} \\
{\left[\mathbf{m} \mathbf{N} \cdot \mathbf{m}^{-\mathbf{1}}\right]}\end{array}$ & $\begin{array}{c}\boldsymbol{\sigma}^{\mathbf{d}} \\
{\left[\mathbf{m} \mathbf{N}^{-\mathbf{1}} \mathbf{]}\right.}\end{array}$ & $\begin{array}{c}\boldsymbol{\sigma}^{\mathbf{p}} \\
{\left[\mathbf{m} \mathbf{N} \cdot \mathbf{m}^{-\mathbf{1}}\right]}\end{array}$ \\
\hline PP-g-starch & 30.4 & 30.4 & 0 \\
\hline PP-g-MA2 & 33.4 & 32.2 & 1.1 \\
\hline PP-g-MA1 & 32.9 & 32.2 & 0.7 \\
\hline PP-g-MA3 & 34.2 & 31.7 & 2.6 \\
\hline
\end{tabular}

Table 5. Calculated interfacial tension $\sigma_{12}$ of the blends

\begin{tabular}{|l|c|}
\hline \multicolumn{1}{|c|}{ Blend } & $\begin{array}{c}\text { Interfacial tension } \boldsymbol{\sigma}_{\mathbf{1 2}} \\
{\left[\mathbf{m ~ N} \cdot \mathbf{m}^{\mathbf{- 1}}\right]}\end{array}$ \\
\hline PP-g-starch/PP-g-MA2 & 7.41 \\
\hline PP-g-starch/PP-g-MA1 & 6.10 \\
\hline PP-g-starch/PP-g-MA3 & 10.42 \\
\hline
\end{tabular}

The interfacial tension $\left(\sigma_{12}\right)$ between the constitutive materials (1 and 2) of the different polymer blends were then calculated from the polymers surface energies and their polar and dispersive components using Wu's harmonic relation (Equation (1)), which has been shown to be applicable to polymer melts $[26,27]$. The calculated values are reported in Table 5 for the different PP-g-starch/PP-g-MA blends:

$\sigma_{12}=\sigma_{1}+\sigma_{2}-\frac{4 \sigma_{1}^{\mathrm{d}} \sigma_{2}^{\mathrm{d}}}{\sigma_{1}^{\mathrm{d}}+\sigma_{2}^{\mathrm{d}}}-\frac{4 \sigma_{1}^{\mathrm{p}} \sigma_{2}^{\mathrm{p}}}{\sigma_{1}^{\mathrm{p}}+\sigma_{2}^{\mathrm{p}}}$

Surface energies were measured and interfacial tensions calculated at room temperature and not at $180^{\circ} \mathrm{C}$ because forming a suitable droplet at such a high temperature was impossible in practice.

\section{Miscibility of PP-g-MA compatibilizers with starch-grafted polypropylene}

At first, the miscibility of the different PP-g-MA compatibilizers (differing by their maleic anhydride grafting level and their molecular weight) with the polymer matrix (PP-g-starch) was checked in order to define the most desirable formulation. The assessment of the miscibility was carried out for the different PP-g-starch/PP-g-MA blends by means of complementary rheological and microscopic characterisation methods.

\subsection{Rheological assessment}

Rheological methods have been frequently used to study the phase separation of partially miscible or immiscible (i.e. fully phase separated) polymer 
blends. One of the most frequently used methods to judge whether the blend is fully miscible (i.e. behaves as a single-phase system with no phase separation) or in phase separated state is the timetemperature superposition (TTS) principle [28, 29]. The TTS principle states that, when studying the viscoelastic behaviour of a material (for instance complex viscosity or complex elasticity modulus), a change of temperature is completely equivalent to a shift of the logarithmic time scale (so-called timeshift); such a material is termed 'thermo-rheologically simple' [30]. It is usually believed that TTS principle fails for polymer blends in phase separated state, and works in miscible state [28, 29]. If an excellent superposition is obtained when plotting
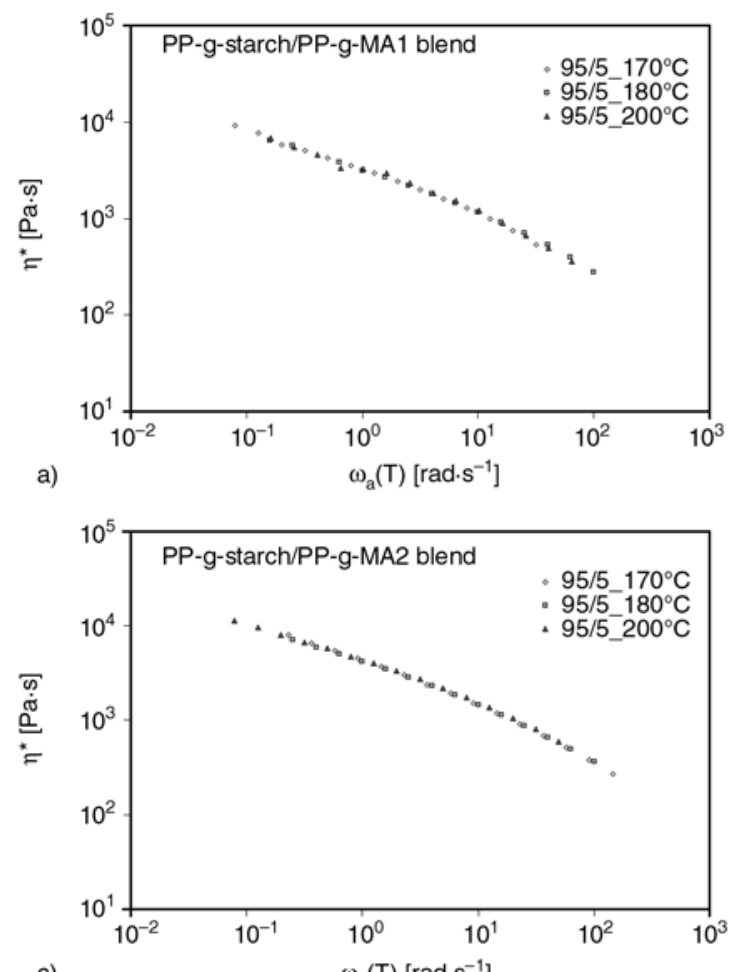

c)

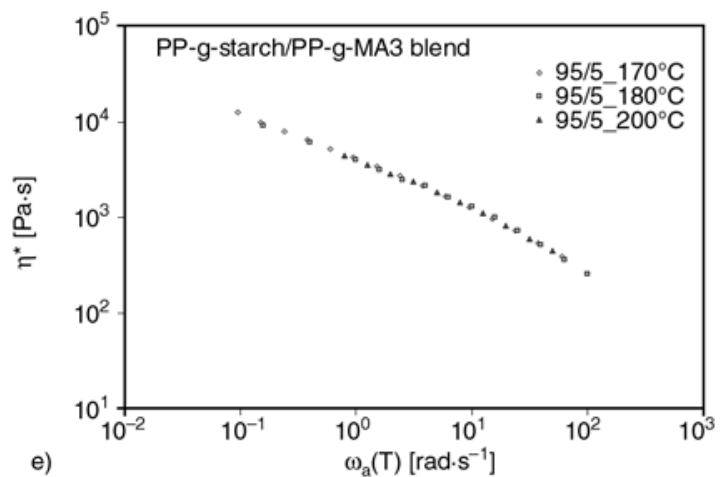

the rheological master curves at a reference temperature, then the polymer blend is fully miscible; if not, it is assumed to be immiscible or partially miscible only.

The dynamic rheological behaviour of $95 / 5$ and 80/20 wt $\%$ PP-g-starch/PP-g-MA blends was recorded at different temperatures, namely 170,180 and $190^{\circ} \mathrm{C}$. The master curves of complex viscosity $\eta^{*}$ as a function of the shifted frequency $\alpha_{T} \omega$ at $180^{\circ} \mathrm{C}$ were plotted (Figure 2). A very good superposition is obtained for the blends containing PP-gMA2 and PP-g-MA3 whatever the compatibilizer weight content. Their rheological behaviour depends neither on the temperature nor on the blend composition (i.e. PP-g-MA weight content), suggesting
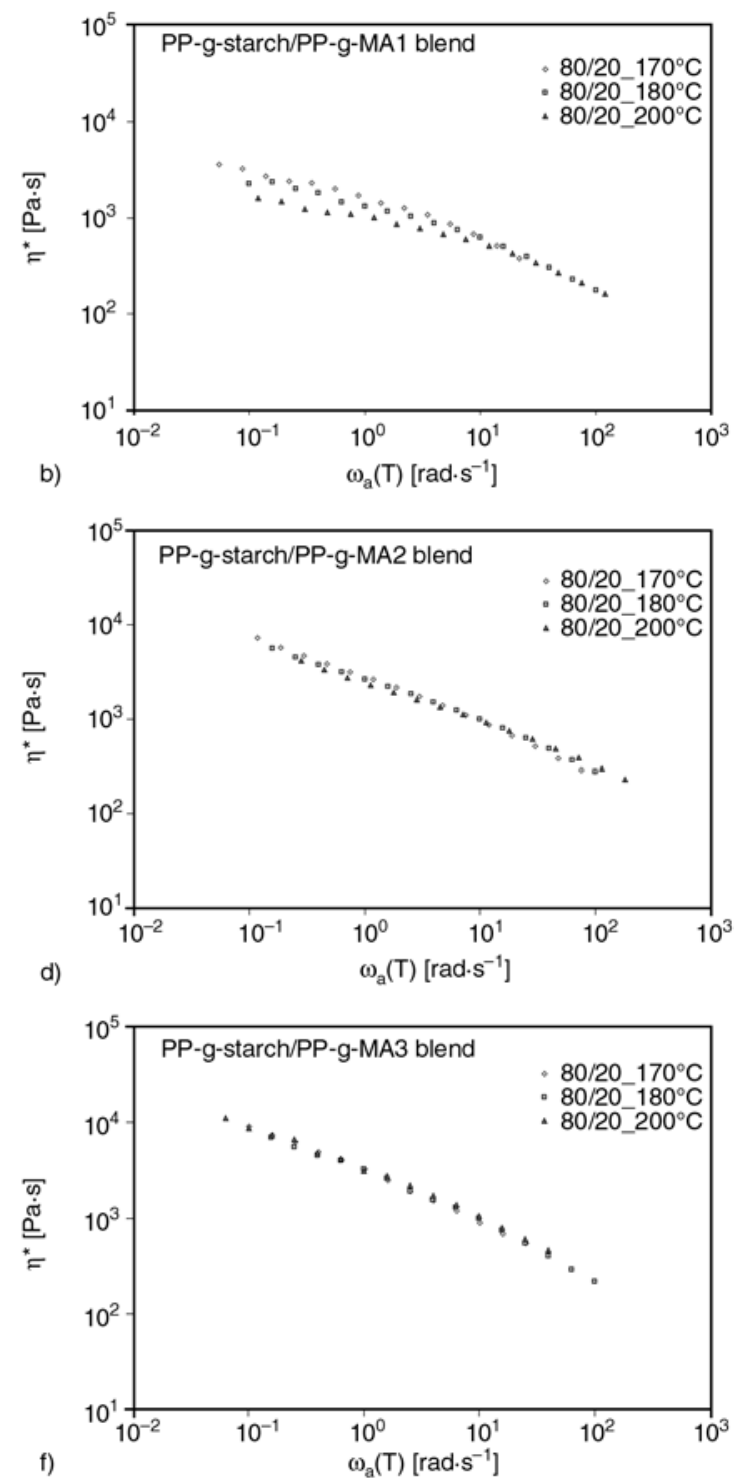

Figure 2. Complex viscosity master curves at the reference temperature of $180^{\circ} \mathrm{C}$ for PP-g-starch/PP-g-MA1 (a, b), PP-gstarch/PP-g-MA2 (c, d) and PP-g-starch/PP-g-MA3 (e, f) compatibilized blends at 95/5 wt\% (a, c, e) and $80 / 20 \mathrm{wt} \%(\mathrm{~b}, \mathrm{~d}, \mathrm{f})$ 
quite good miscibility. A peculiar behaviour is noticed in the case of the blend containing PP-gMA1; a shift appears at lower frequencies depending on both the temperature and the PP-g-MA weight content. Such a deviation may be ascribed to a partial, lower miscibility of this blend, in particular when the compatibilizer weight content is high. A similar trend was also pointed out by other authors [10]. It is however worth mentioning that the failure of TTS principle is not a strict principle to judge the phase separation as it may fail in the miscible state also according to some authors [28]. Therefore, another complementary method was also implemented.

\subsection{Microscopic assessment and prediction of dispersed particle size}

As a method of direct observation, optical or electron micron microscopy has also been used quite often to show whether polymer blends are in homogeneous or phase separated states. SEM imaging of

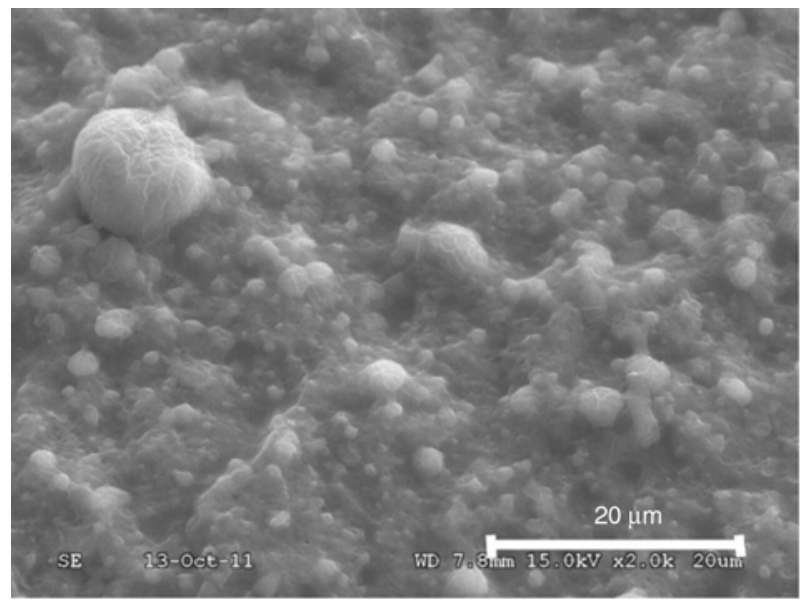

a)

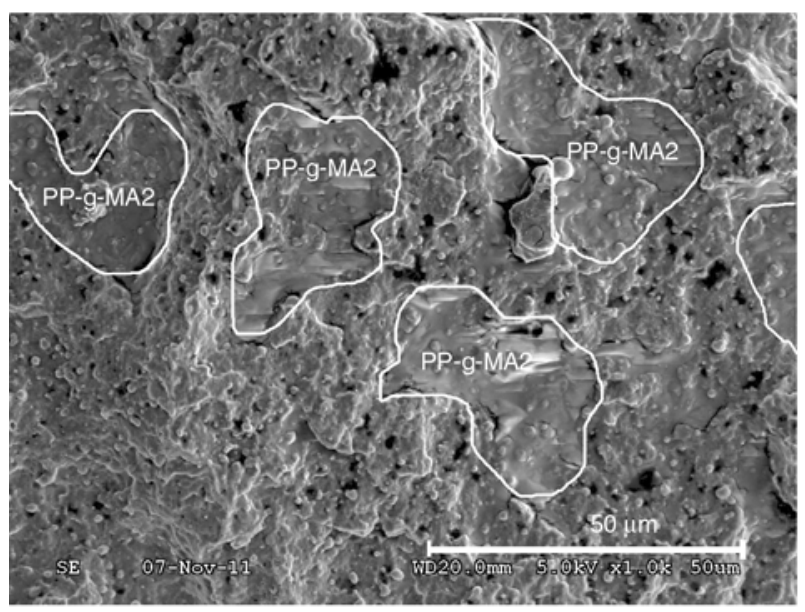

c) neat PP-g-starch and of the three PP-g-starch/PP-gMA blends were performed. Taking the neat biphasic PP-g-starch matrix (Figure 3a) as a reference (further considered being the continuous matrix phase), a PP-g-MA dispersed phase possibly appears upon compatibilizers' addition, depending on PP-gMA type and content. SEM imaging of the three PPg-starch/PP-g-MA blends does not show any significant immiscibility at the lower PP-g-MA compatibilizer content ( $5 \mathrm{wt} \%$ ). At higher weight content ( $20 \mathrm{wt} \%$ ), the dispersed phase size is high enough to be visible on microscopic images (Figure 3b, c, d), but strongly depends on the compatibilizer used. Based on representative SEM images, an equivalent diameter of dispersed phase was determined (typical order of magnitude only). For the PP-g-MA1 homopolymer-based compatibilizer, the size of the dispersed phase typically reaches more than $80 \mu \mathrm{m}$ (Figure $3 \mathrm{~b}$ ) whereas it is of about $35 \mu \mathrm{m}$ for the PPg-MA2 homopolymer-based compatibilizer (Figure $3 \mathrm{c}$ ) and of $25 \mu \mathrm{m}$ for the PP-g-MA3 copolymer-

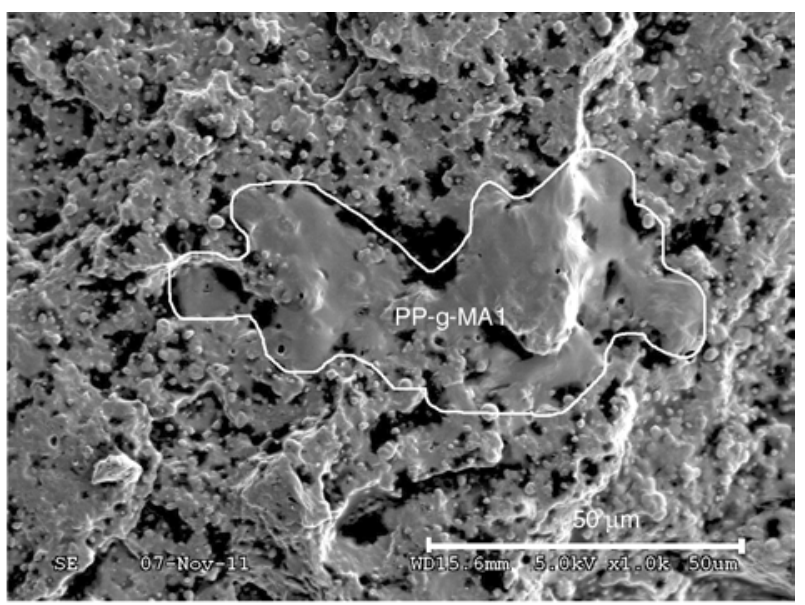

b)

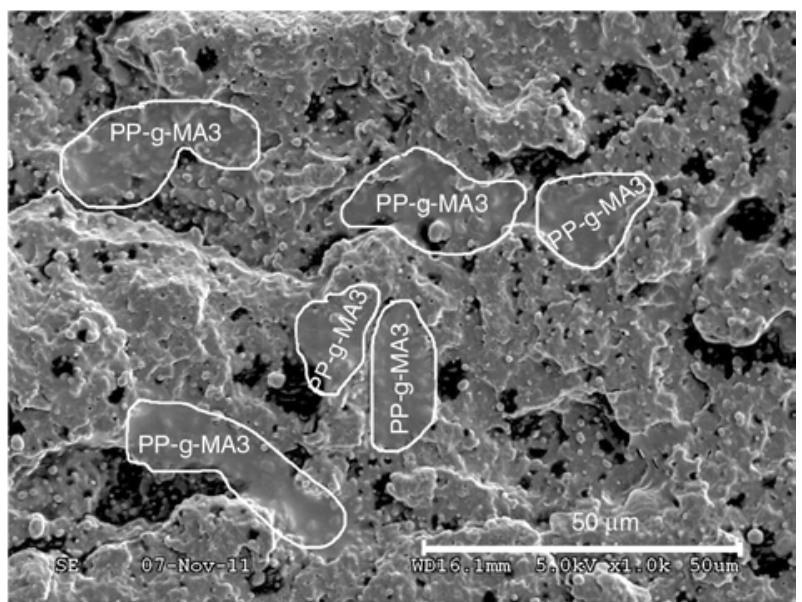

d)

Figure 3. SEM images of cryo-fractured surfaces of (a) neat PP-g-starch; (b) 80/20 wt\% PP-g-starch/PP-g-MA1; (c) 80/20 wt\% PP-g-starch/PP-g-MA2; (d) 80/20 wt\% PP-g-starch/PP-g-MA3 
based compatibilizer (Figure 3d). These particle size differences may explain the difference of rheological behaviour of the blends observed previously, and especially the peculiar behaviour of PPg-MA1 based blends (see 3.1.).

The average particle size in incompatible polymer blends may be predicted using the theory being developed by Wu (Equation (2)) [26]. The disperseddrop size is the smaller when the interfacial tension is the lower and the components viscosity ratio is the closer to unity. Serpe et al. [31] further modified Wu's equation in order to take into account the influence of the dispersed phase concentration and the blend viscosity on blend morphology (Equation (3)):

$$
\begin{aligned}
& D \approx \frac{4 \sigma_{12}}{\dot{\gamma} \eta_{\text {blend }}}\left(\frac{\eta_{\text {disp }}}{\eta_{\text {cont }}}\right)^{\alpha} \\
& D \approx \frac{4 \sigma_{12}}{\dot{\gamma} \eta_{\text {blend }}}\left(\frac{\eta_{\text {disp }}}{\eta_{\text {blend }}}\right)^{\alpha} \\
& 1-\left(4 \cdot\left(\Phi_{\text {disp }} \cdot \Phi_{\text {cont }}\right)^{0.8}\right)
\end{aligned}
$$

where ' $D$ ' is the diameter of the droplet of dispersed phase, $\sigma_{12}$ the interfacial tension between the two components of the blend at a temperature equal to the mixing temperature, $\dot{\gamma}$ the shear rate during mixing, $\eta_{\text {disp }}$ the dispersed phase viscosity, $\eta_{\text {cont }}$ the continuous (matrix) phase viscosity, $\eta_{\text {blend }}$ the blend viscosity, and $\varphi$ disp and $\varphi$ cont the volume fractions of dispersed and continuous matrix phases. $\eta_{\text {disp }} / \eta_{\text {cont }}$ and $\eta_{\text {disp }} / \eta_{\text {blend }}$ are named viscosity ratio and corrected viscosity ratio. $\alpha$ is an experimental parameter, and has a value of nearly 0.84 , which is positive if the corrected viscosity ratio is larger than one and negative if the viscosity ratio is smaller than one.

Dynamic viscosity measurements (Figure 4) show that the rheological behaviour of PP-g-MA3 com-

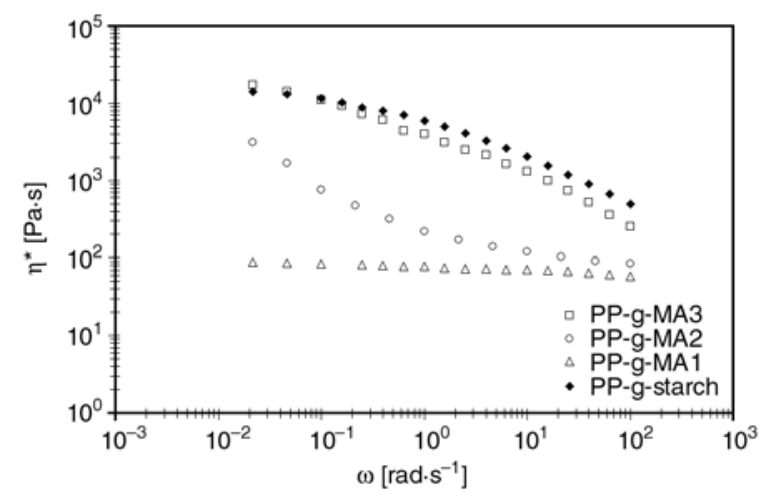

Figure 4. Dynamic rheological behaviour of the blend constituents patibilizer is similar to that of neat PP-g-starch at the reference temperature $\left(180^{\circ} \mathrm{C}\right)$ in the $0.01-$ $100 \mathrm{rad} \cdot \mathrm{s}^{-1}$ frequency range. This means that the finest dispersed-droplet size is expected in that case. At the processing shear rate $\left(\dot{\gamma}=120 \mathrm{~s}^{-1}\right)$, the blend viscosities of the two homopolymer compatibilizers (PP-g-MA1 and PP-g-MA2) are similar and lower than the PP-g-starch viscosity; the dispersed droplets should be larger. The theoretical particle sizes of the dispersed phase were calculated from the Serpe's model (Equation (3)) for each blend. They are around 2 to $4 \mu \mathrm{m}$ for the $95 / 5 \mathrm{wt} \% \mathrm{PP}$-gstarch/PP-g-MA blends. The theoretical particle diameter of PP-g-MA1 is two times higher than that of the other compatibilizers, but the differences remains low in the considered shear rate range. When PP-g-MA content reaches $20 \mathrm{wt} \%$, the theoretical particle diameter increases up to 7.5, 8.8 and $20 \mu \mathrm{m}$ for PP-g-MA3, PP-g-MA2 and PP-g-MA1 compatibilizers respectively (Figure 5 ). The hierarchy previously obtained on the basis of representative SEM observations $(25,35$ and $80 \mu \mathrm{m}$ respectively) is confirmed. The differences between experimental and theoretical values may be explained by the fact that the interfacial tensions values used in computations were determined at room temperature and not at the mixing temperature for practical reasons (see 2.7.).

To summarize, even if major immiscibility of the compitibilizers used with PP-g-starch was not evidenced, the PP-g-MA3 copolymer compatibilizer gives the best results in terms of dispersed particle sizes and thus of miscibility thanks to its rheological behaviour close to that of the PP-g-starch matrix. The addition of PP-g-MA1 compatibilizer leading

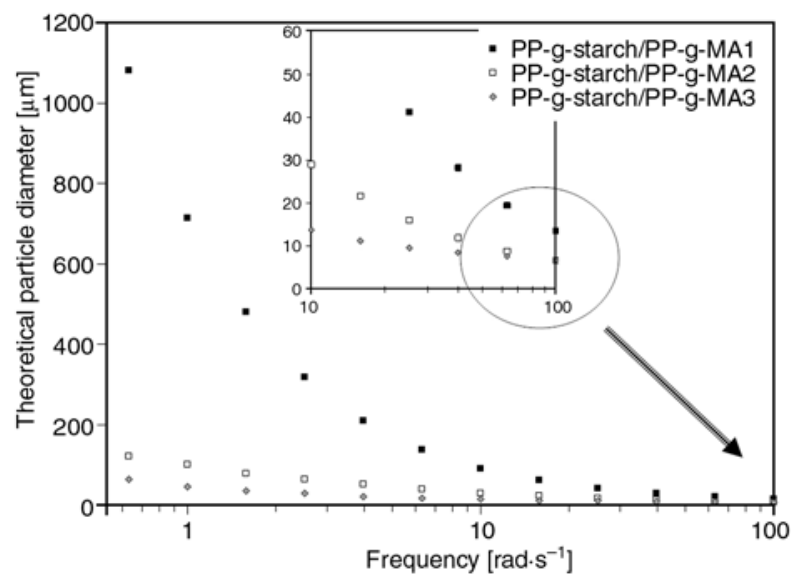

Figure 5. Calculated diameter of $20 \mathrm{wt} \%$ PP-g-MA dispersed phase in the PP-g-starch matrix as function of frequency 
to lower miscibility (large dispersed particle size), further investigations will be carried out using PPg-MA2 homopolymer-based and PP-g-MA3 copolymer-based compatibilizers.

\section{Reinforcement of starch-grafted polypropylene with nanoclay}

In a second development step, nanoclay was added to the compatibilized starch-grafted polypropylene, aiming at forming ternary PP-g-starch/PP-g-MA/ organoclay nanocomposites with improved mechanical properties. Dispersion, intercalation and exfoliation of nanoclay is a key factor to achieve this goal.

\subsection{Assessment of clay dispersion, intercalation and exfoliation in ternary PP-g-starch/PP-g-MA/clay hybrids}

When assessing the structure of nanocomposites, the main issue is to get a representative evaluation of the filler dispersion degree at a relevant scale. Microscopy is widely used but provides local and qualitative assessment only. Alternatively, dynamic (oscillatory) rheology may provide a semi-quantitative evaluation of the dispersion degree of nanofillers such as carbon nanotubes or layered silicates (montmorillonite among others) in the bulk $[8,18$, 32-35]. Also, X-ray diffraction (XRD) analysis allows quantifying the intercalation in the bulk by measuring the clay platelets interlayer distance [35].

\section{Influence of clay organo-modification}

Transmission Electron Microscopy (TEM) shows that, whatever the material formulation, clay is locally well dispersed (see for example Figure 6a and $6 \mathrm{c}$ for 5PP-g-MA3 C30B and 5PP-g-MA2 C20A references respectively). The presence of clay tactoids and several individual clay platelets indicates an intercalated structure with partial exfoliation (Figure $6 \mathrm{~b}$ and $6 \mathrm{~d}$ ). No significant difference is visible at this local scale between the different materials. As a consequence, rotational rheology and $\mathrm{XRD}$ were used in this section to further investigate the effect of the clay surfactant and PP-g-MA compatibilizer on nanoclay dispersion, intercalation and exfoliation and to get a more global assessment.

The dynamic rheological analysis (Figure 7) does not reveal any major difference between the two organo-modified polar (C30B) and non-polar (C20A) clays whatever the PP-g-MA compatibilizer type, the secondary plateau of storage modulus tending to appear in both cases. Nevertheless, compared to its non-polar counterpart, the polar organo-modified clay (C30B) has a higher storage modulus and a slightly lower terminal slope in the low frequency domain, which suggests a better clay dispersion degree, intercalation and/or exfoliation in that case. Actually, it is well admitted that the exfoliated and/or disordered intercalated silicate layers form a network type structure rendering the system highly elastic as revealed by the appearance of a secondary plateau for the dynamic storage modulus $\left(G^{\prime}\right)$ in the low frequency regime (i.e. frequency independent behaviour at the lower frequencies) or at least a lower terminal slope in $G^{\prime}$ vs. frequency $(\omega)$ plot. This gradual change of the behaviour from liquidlike to solid-like is mainly correlated to the extent of dispersion and distribution of the nanofillers that form a three-dimensional percolating network.

Based on XRD analysis (Figure 8), the space gallery was determined using the Bragg law for the organoclays and the blends containing nanoclay. A decrease in the degree of coherent layer stacking (i.e. a more disordered system) of the clay would lead to a peak broadening and an intensity decrease in the XRD diffractogram. The primary $\left(d_{001}\right)$ diffraction peaks of neat $\mathrm{C} 20 \mathrm{~A}$ and $\mathrm{C} 30 \mathrm{~B}$ are located around $2 \theta=4$ and $5.4^{\circ}$ respectively, which gives interlayer spacing (d-spacing) of 1.55 and $0.81 \mathrm{~nm}$ respectively. Upon addition of C20A clays into PP-g-starch/PPg-MA blend, the XRD peak shifts to lower angles around $2 \theta=2.56^{\circ}$ (or even vanishes tending to form a shoulder in case of PP-g-MA3) indicating an increase in interlayer spacing due to polymer intercalation within clay platelets (confirmed by TEM imaging, Figure 6d). The average distance between the platelets then becomes about $2.99 \mathrm{~nm}$ instead of $1.55 \mathrm{~nm}$ before intercalation. In the case of the C30B-based blends, the absence of the signal in the XRD pattern tends to suggest the existence of clay platelets exfoliation.

The maleic anhydride of the PP-g-MA compatibilizer can interact with both the polar organo-modified clay (C30B) and the starch phase of the matrix according to the chemical reactions presented in Figure 9. The C30B surfactant has two hydroxyl groups $(-\mathrm{OH})$ that can react with the PP-g-MA anhydride (-CO-O-CO-) to give an ester (- $\mathrm{COO}-)$ and an acid $(-\mathrm{COOH})$ (Figure $9 \mathrm{a}$ and $9 \mathrm{~b})$. The acid 


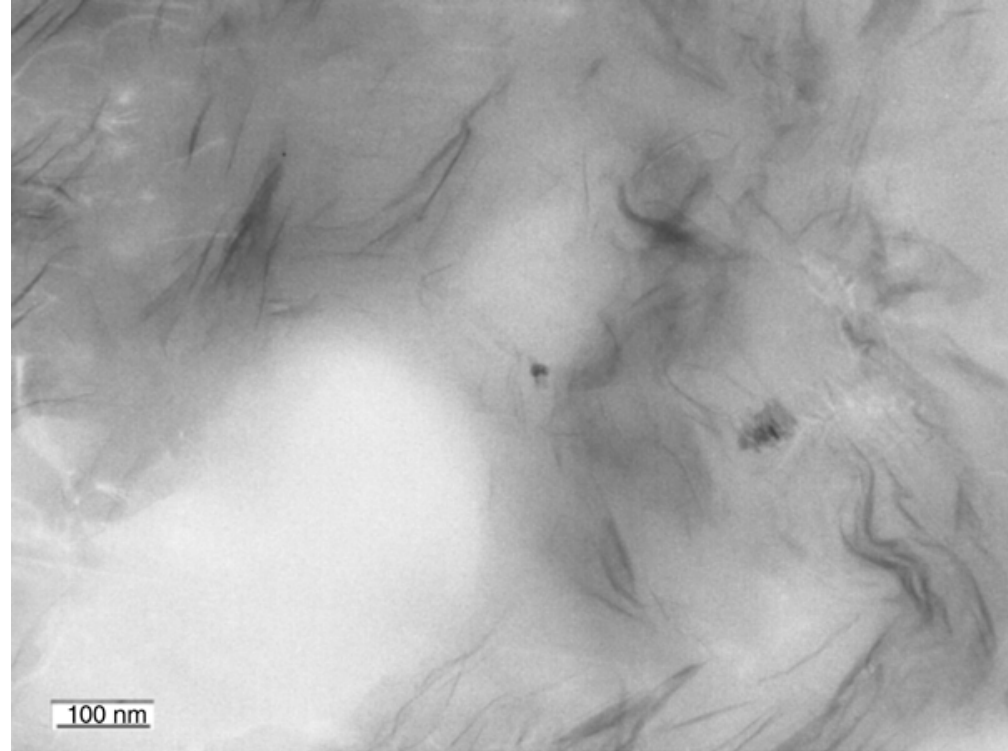

a)

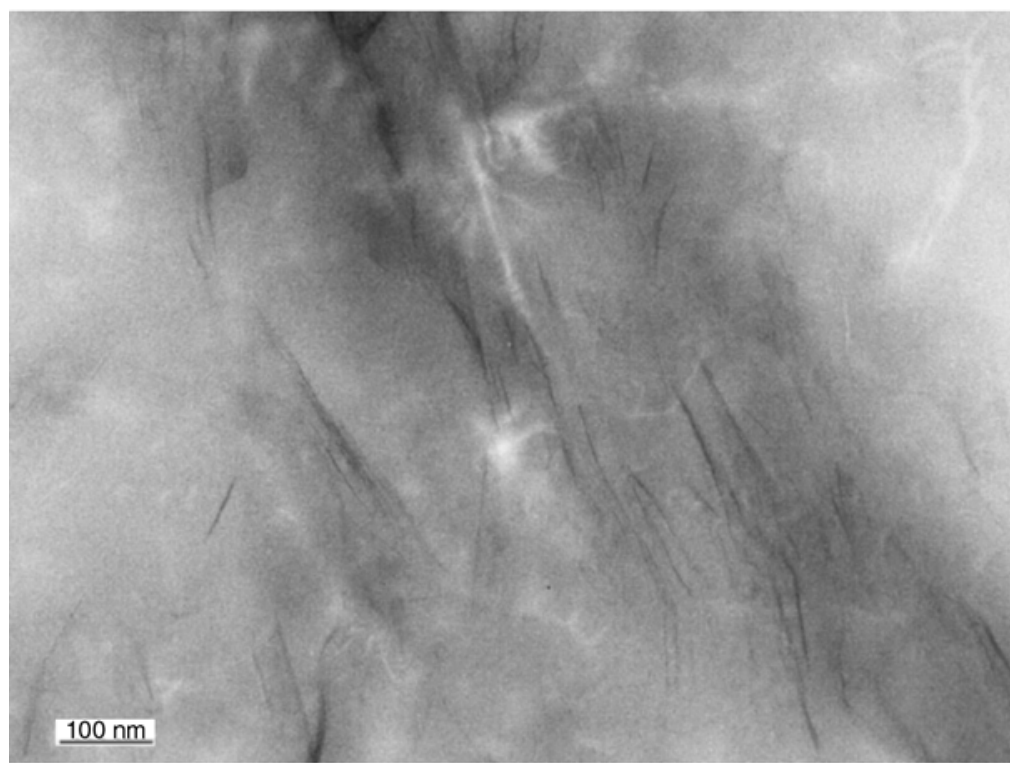

c)

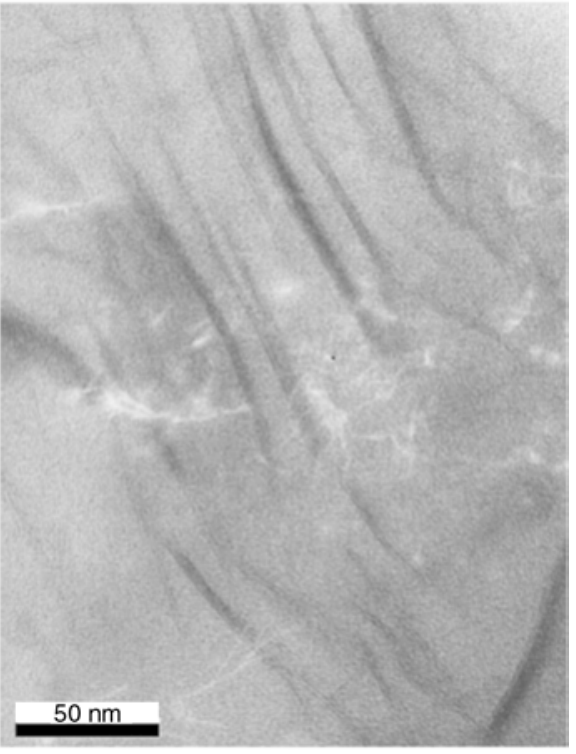

b)

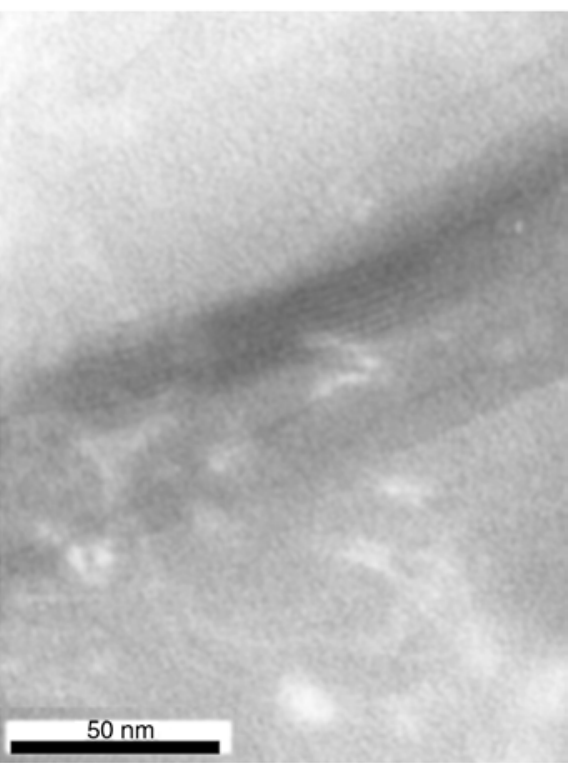

d)

Figure 6. TEM images of PP-g-starch/PP-g-MA/organoclay hybrids. (a, b) 5PP-g-MA3 C30B, (c, d) 5PP-g-MA2 C20A, at lower $(\mathrm{a}, \mathrm{c})$ and $(\mathrm{b}, \mathrm{d})$ higher magnifications
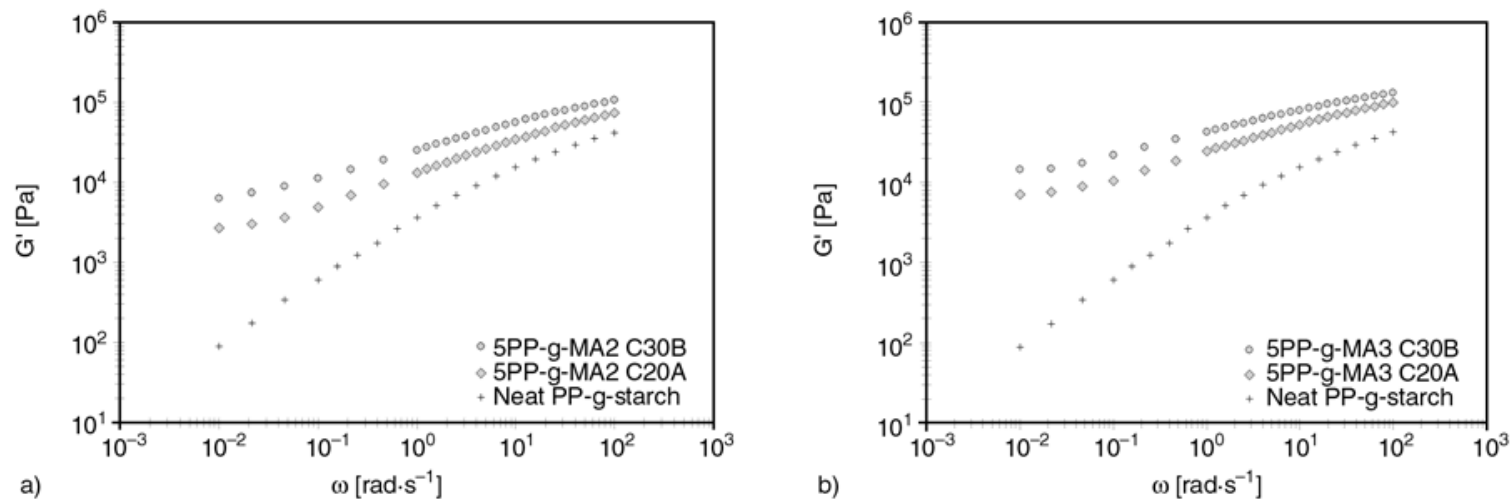

Figure 7. Influence of MA-grafting level of PP-g-MA ( $1 \mathrm{wt} \%$ for PP-g-MA2 and $1.4 \mathrm{wt} \%$ for PP-g-MA3) on storage modulus of PP-g-starch/5 wt\%PP-g-MA/organoclay hybrids for different organoclays: (a) C30B ; (b) C20A 


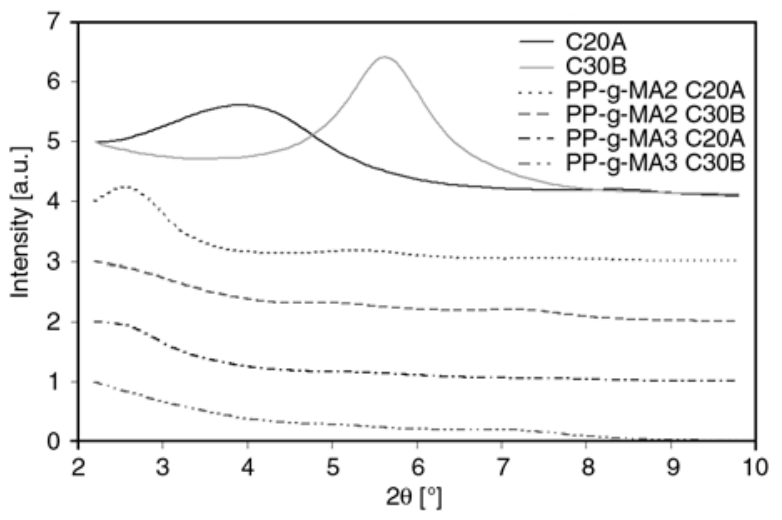

Figure 8. Influence of clay organo-modification (C20A or C30B) on X-ray diffraction patterns of PP-gstarch $/ 5 \mathrm{wt} \%$ PP-g-MA/organoclay hybrids for different PP-g-MA

group can then react with the second hydroxyl of the surfactant (or coming from another part of the surfactant) to form a second ester and a water molecule (Figure 9c). On the other hand, maleic anhydride can react with the numerous hydroxyl groups of the starch which is mainly constituted of amylose and amylopectine. All these chemical reactions favour the formation of a surfactant/PP-g-MA/starch network making the platelet separation, intercalation and exfoliation (at least partially) possible and therefore increasing the dynamic storage modulus. In the case of the non-polar organo-modified clay (C20A), the long alkyl chains of the surfactant intercalate the platelets to form a paraffin film facilitating the exfoliation, as suggested by Alexandre and Dubois [36]. This is supported by the fact that, as mentioned above, the initial inter-platelet distance of this non-polar modified montmorillonite (C20A) is higher than that of its polar modified counterpart (C30B) $(1.55 \mathrm{~nm}$ against $0.81 \mathrm{~nm})$. In case of C20A, the exfoliation mechanism is more mechanically driven (by polypropylene chain insertion) than chemically driven.

Globally, whatever the PP-g-MA compatibilizer, the addition of polar organoclay (C30B) seems to be preferable rather than non-polar organoclay $(\mathrm{C} 20 \mathrm{~A})$ as the former allows achieving better clay dispersion degree and exfoliation level and therefore higher dynamic storage modulus.

\section{Influence of PP-g-MA content and MA-grafting level}

Increasing the MA-grafting level of PP-g-MA from $1 \mathrm{wt} \%$ (PP-g-MA2) to $1.4 \mathrm{wt} \%$ (PP-g-MA3) increases the storage modulus and slightly decreases the terminal slope in the low frequency domain (Figure 10), apparently slightly more for $\mathrm{C} 20 \mathrm{~A}$ than for $\mathrm{C} 30 \mathrm{~B}$ organoclay. This suggests that PP-g-MA3 has a better ability to promote clay intercalation and partial exfoliation of the non-polar organoclay (C20A) that is confirmed by XRD analysis (vanishing of the $\mathrm{C} 20 \mathrm{~A}$ residual peak, shoulder appearing at low angles, Figure 8). As PP-g-MA2 and PP-gMA3 have similar molecular weights (89000 and $88700 \mathrm{~g} \cdot \mathrm{mol}^{-1}$ respectively), a higher molecular mobility and lower rigidity of the PP-g-MA3 maleated ethylene-propylene copolymer (compared to the maleated homopolymer PP-g-MA2) due to the $52 \mathrm{wt} \%$ ethylene content in the copolymer, may also contribute to explain this better efficiency.

Increasing the PP-g-MA compatibilizer weight content from 5 to $20 \mathrm{wt} \%$ is either not significant (in the case of PP-g-MA2) or detrimental (in the case of PP-g-MA3) (Figure 11). In particular for C20A, the storage modulus drops by nearly a decade when

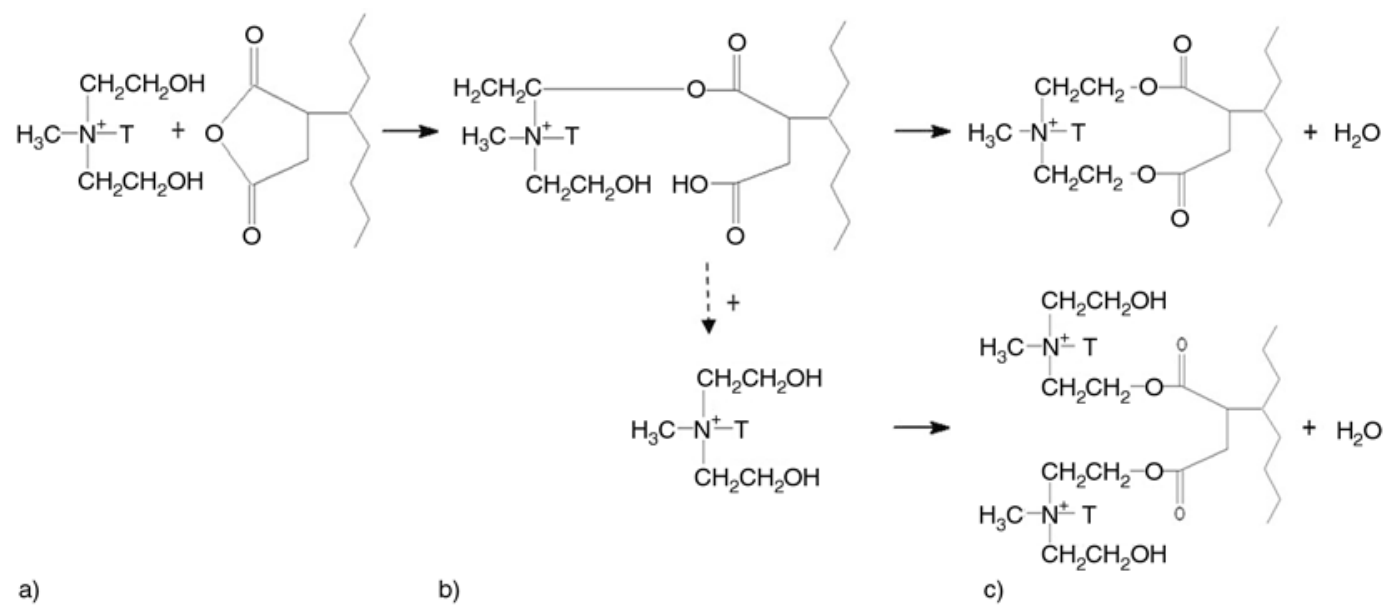

Figure 9. Expected chemical reactions of $\mathrm{C} 30 \mathrm{~B}$ polar organo-modified clay and PP-g-MA compatibilizer (a) to form an ester and acid groups (b); final ester chemical structure (c) 

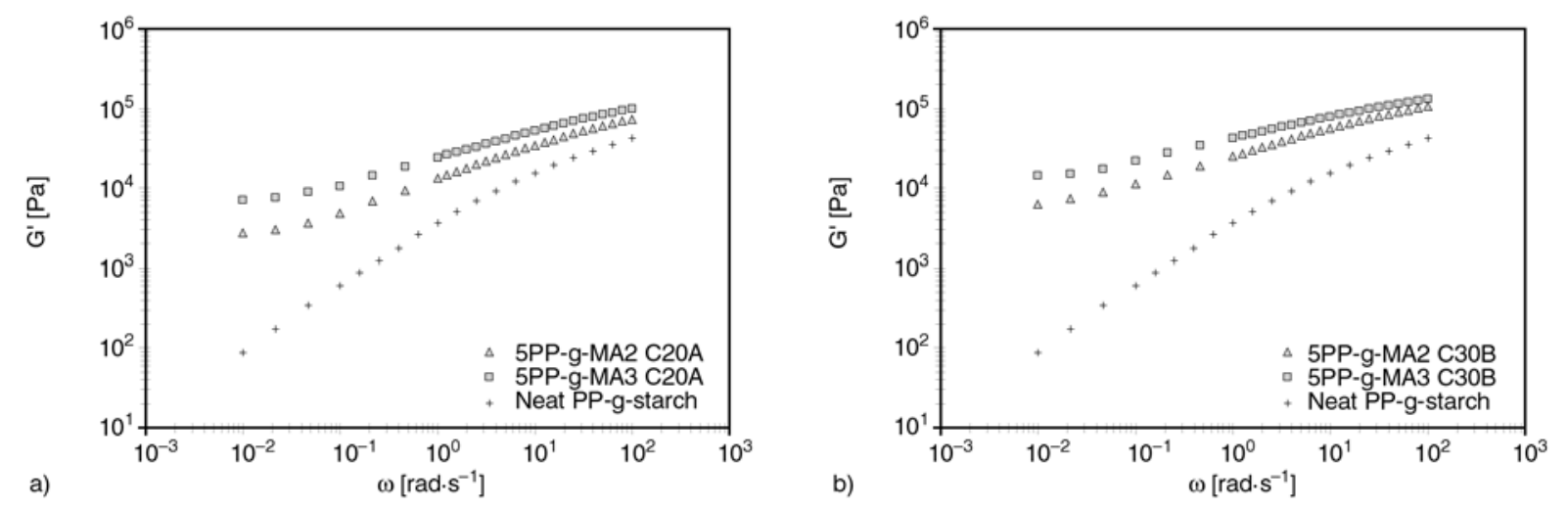

Figure 10. Influence of MA-grafting level of PP-g-MA ( $1 \mathrm{wt} \%$ for PP-g-MA2 and $1.4 \mathrm{wt} \%$ for PP-g-MA3) on storage modulus of PP-g-starch/5 wt \%PP-g-MA/organoclay hybrids for different organoclays: (a) C30B; (b) C20A
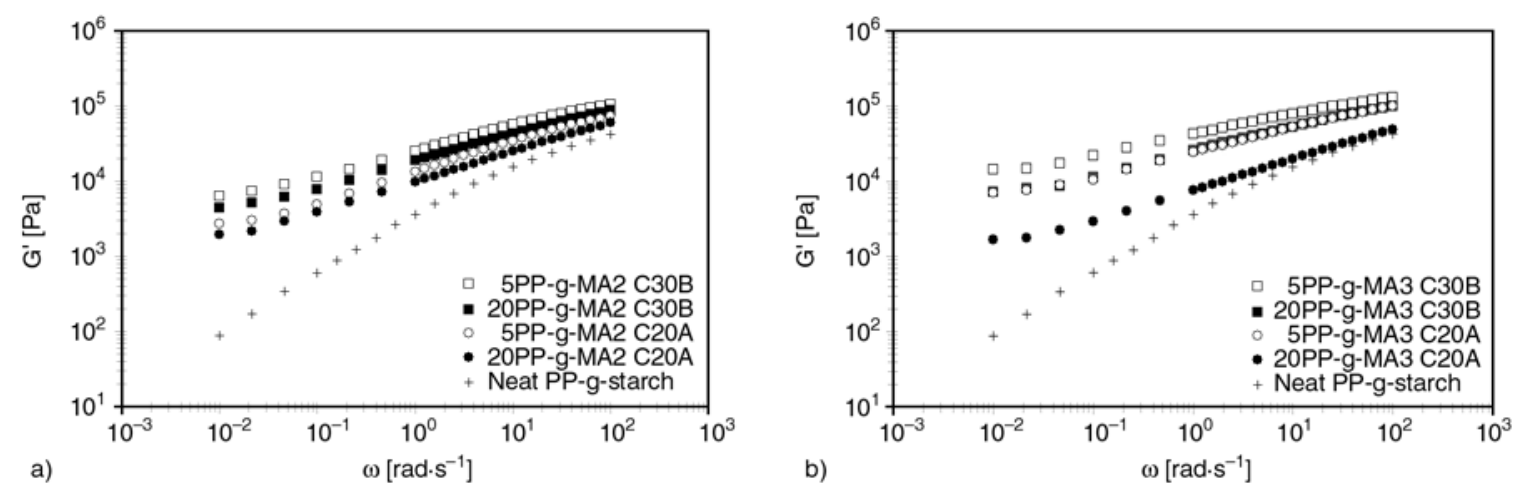

Figure 11. Influence of PP-g-MA content (5 or $20 \mathrm{wt} \%$ ) on storage modulus of PP-g-starch/PP-g-MA/organoclay hybrids for different organoclays (C30B or C20A) and PP-g-MA types: (a) PP-g-MA2; (b) PP-g-MA3

the PP-g-MA3 content is multiplied by 4. This may be ascribed to the lower modulus of the PP-g-MA based on ethylene-propylene copolymer. The XRD patterns do not show any significant differences when PP-g-MA weight content increases (therefore not reported here).

To summarize, adding at moderate weight content (5 wt\%) an ethylene-propylene copolymer-based PP-g-MA compatibilizer having high MA-grafting level and a polar modified montmorillonite (C30B) seems to be the most desirable combination to optimize the clay dispersion, intercalation and exfoliation in PP-g-starch/PP-g-MA/organoclay hybrids.

\subsection{Mechanical properties of ternary PP-g-starch/PP-g-MA/clay hybrids}

The tensile mechanical properties of the ternary PPg-starch/PP-g-MA/organoclay hybrids were determined and are plotted as a function of the maleic anhydride fraction in the total PP phase (i.e. PP contained in both PP-g-starch and PP-g-MA) in Figures 12 (Young's modulus), 13 (yield stress), 14 (strength, i.e. stress at break) and 15 (elongation at

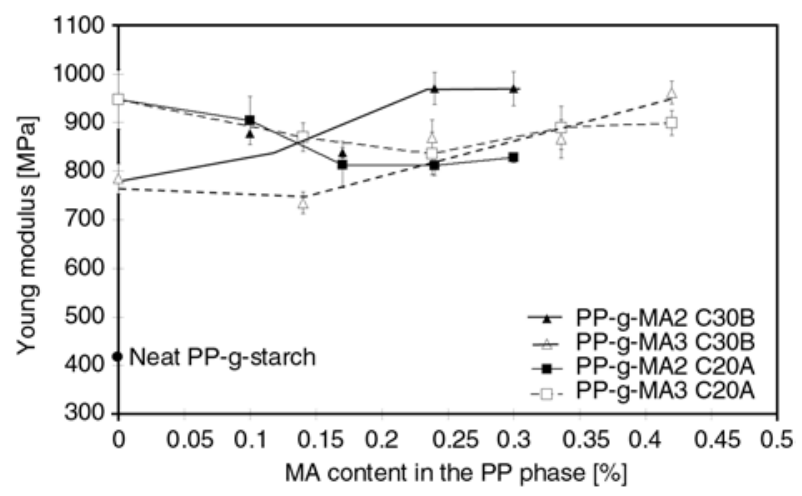

Figure 12. Influence of clay organo-modification (C20A or C30B) and PP-g-MA compatibilizer on nancomposites Young's modulus

break). The weight content of the added PP-g-MA is therefore taken into account in an implicit manner.

Addition of $3.5 \mathrm{wt} \%$ of mineral (neat mineral corresponding to $5 \mathrm{wt} \%$ organoclay) into PP-g-starch clearly increases its tensile modulus (Figure 12) by 100 or $130 \%$ depending on the organoclay type (polar organo-modified C30B or non-polar organomodified C20A, respectively). However, addition of polar PP-g-MA compatibilizer induces opposite 
effects depending on the clay surfactant polarity. Whereas the modulus increases (up to $+20 \%$ ) as a function of MA fraction for polar C30B-based compounds, it decreases (up to $-15 \%$ ) for non-polar C20A-based compounds. These results confirm that clay platelets intercalation is mechanically-driven in the case of CA20 (no possible chemical reactions) and chemically-driven in the case of $\mathrm{C} 30 \mathrm{~B}$ (existence of chemical reactions between the maleic anhydride of PP-g-MA and the hydroxyl groups of the surfactant).

Similarly, addition of nanoclay into PP-g-starch increases its tensile yield stress (Figure 13) by 10 or $15 \%$, depending on the organoclay type (polar organo-modified $\mathrm{C} 30 \mathrm{~B}$ or non-polar organo-modified $\mathrm{C} 20 \mathrm{~A}$, respectively). Besides, the yield stress further increases significantly (up to $+15 \%$ ) as a function of the MA fraction increase for both organoclay types.

The effect of nanoclay addition on ultimate properties is quite different and strongly depends on clay organo-modification type. Addition of $3.5 \mathrm{wt} \%$ of mineral into PP-g-starch changes its strength (Fig-

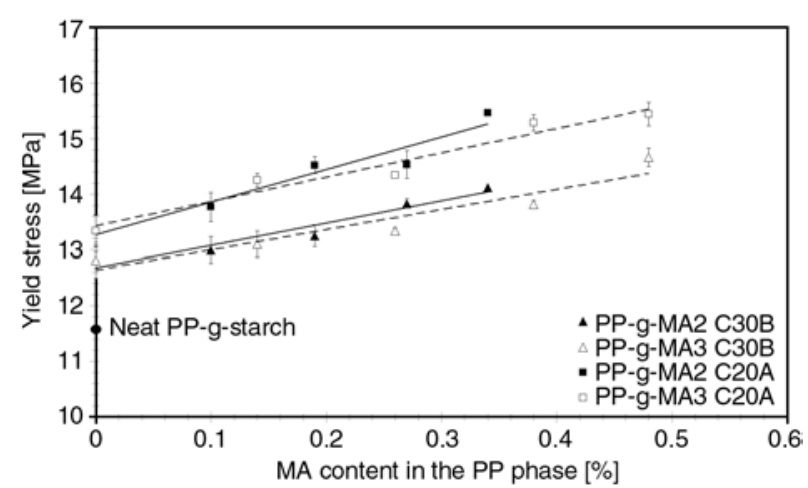

Figure 13. Influence of clay organo-modification (C20A or C30B) and PP-g-MA compatibilizer on nanocomposites yield stress

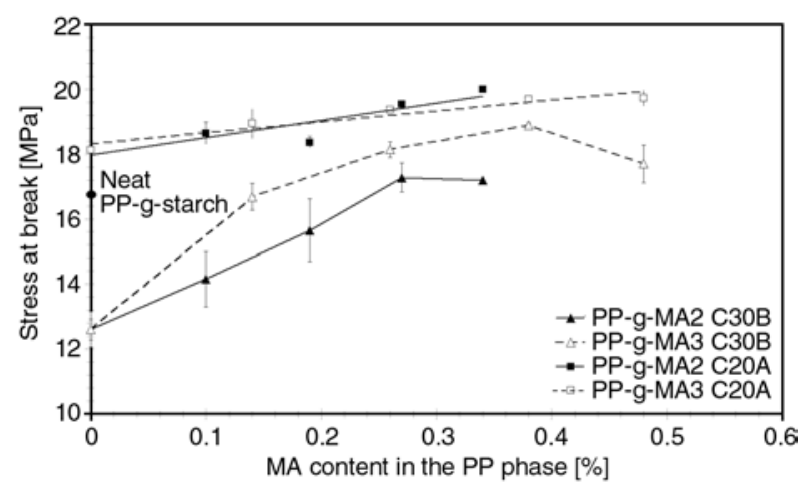

Figure 14. Influence of clay organo-modification (C20A or C30B) and PP-g-MA compatibilizer on nanocomposites strength (stress at break) ure 14) in a manner being either detrimental or favourable, by -25 or $+6.5 \%$, depending on the organoclay type (polar organo-modified C30B or non-polar organo-modified C20A, respectively). As for the strength, addition of compatibilizer at growing MA level then increases the strength significantly: moderately for C20A-based materials (up to $+10 \%$ ) and very importantly for C30B-based materials (up to +36 or even $+48 \%$ depending on the compatibilizer type, possibly above the initial value of neat PP-g-starch for PP-g-MA3).

As expected, the elongation at break is also affected (Figure 15). Adding $3.5 \mathrm{wt} \%$ of mineral has almost no effect on PP-g-starch ductility (elongation at break decreases by $-10 \%$ only) for $\mathrm{C} 20 \mathrm{~A}$, whereas it strongly reduces deformation ability (elongation at break drops by $-40 \%$, from about $600 \%$ to less than $375 \%$ ) for $\mathrm{C} 30 \mathrm{~B}$ due to the presence of clay aggregates in the sample. In this latter case, addition of PP-g-MA compatibilizers makes it possible to limit to $[-20 \% ;-10 \%]$ or even to nearly avoid (case of PP-g-MA3) the loss of ductility.

Such an increase in tensile yield stress and strength may be ascribed to improved matrix/clay interfacial interactions [10], better miscibility between PP-gMA and PP-g-starch macromolecules and improved interfacial affinity between polymer phases brought by clays surfactant (well known double role of clay acting as structural reinforcement and compatibilizer in polymer blends [19-23] as shown by Yousfi et al. [24]).

The efficiency differences in term of usage properties improvement observed between non-polar C20A and polar $\mathrm{C} 30 \mathrm{~B}$ organoclays, the former having affinity with PP phase and the latter with the starch phase of PP-g-starch matrix [11, 12], may be

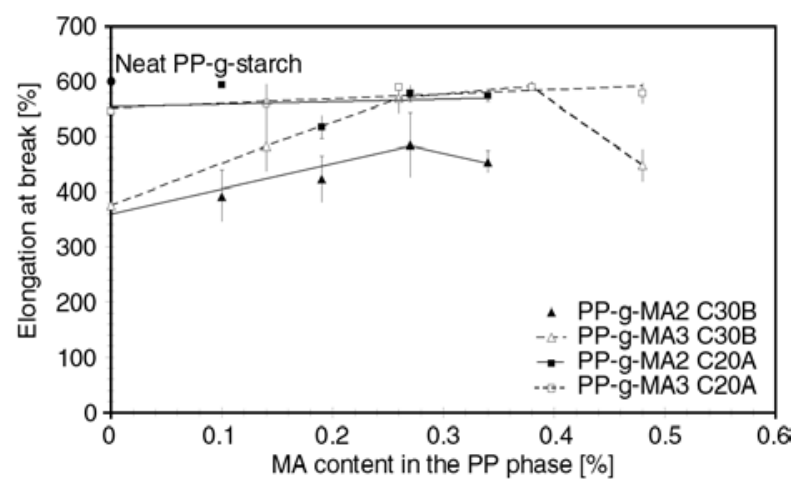

Figure 15. Influence of clay organo-modification (C20A or C30B) and PP-g-MA compatibilizer on nanocomposites elongation at break 
explained considering the chemical composition and structure of PP-g-starch. The long PP chain mobility may be assumed being higher than that of grafted starch chains because of steric hindrance issues. Moreover, considering the $\mathrm{PP} /$ starch weight ratio within PP-g-starch (48\% PP and 52\% starch) and the respective molecular masses of PP $\left(42.08 \mathrm{~g} \cdot \mathrm{mol}^{-1}\right)$ and starch $\left(162 \mathrm{~g} \cdot \mathrm{mol}^{-1}\right)$ repeating units, the molar ratio is $1 / 0.28$. When the material is subjected to tensile loading, the PP segments predominantly sustain stresses and strains whereas grafted starch segments follow this main skeleton chain movement and mostly undergo shear and compression. Considering $\mathrm{C} 20 \mathrm{~A} / \mathrm{PP}$ and $\mathrm{C} 30 \mathrm{~B} / \mathrm{starch}$ above-mentioned affinities, it makes sense to suppose that the non-polar modified clay (C20A) is preferentially dispersed in the PP phase whereas the polar modified clay (C30B) is mainly dispersed in the starch polar phase. Despite better exfoliation obtained with C30B clay within the starch phase, previously evidenced by XRD and dynamic rheology, C20A intercalated clay efficiently reinforces the phase (PP) governing the PP-g-starch deformation, damage and fracture mechanisms under tensile loading.

As a consequence, whatever the PP-g-MA compatibilizer (PP-g-MA2 or PP-g-MA3), the addition of non-polar organoclay $(\mathrm{C} 20 \mathrm{~A})$ is preferably recommended rather than polar organoclay $(\mathrm{C} 30 \mathrm{~B})$ to achieve higher tensile properties (modulus, yield stress, strength) without significant loss of ductility in PP-g-starch/PP-g-MA/organoclay hybrids.

\section{Conclusions}

Novel nanocomposites based on durable, $52 \mathrm{wt} \%$ plant-based, starch-grafted polypropylene (PP-gstarch) and organo-modified montmorillonite compatibilized with polypropylene-grafted-maleic anhydride (PP-g-MA) were successfully prepared by melt-compounding in a co-rotating twin-screw extruder. Two types of organoclay (same montmorillonite with different surfactants) were considered: Cloisite ${ }^{\circledR} 30 \mathrm{~B}$ having affinity with the starch phase due to its polar functional groups, and Cloisite ${ }^{\circledR} 20 \mathrm{~A}$ having affinity with the polypropylene phase of the polymer matrix due to its nonpolar groups. Homopolymer or copolymer-based
PP-g-MA with different molecular weights and different maleic anhydride (MA) grafting levels was added at different weight contents as compatibilizer to improve clay dispersion.

Whatever the formulation, no significant immiscibility of PP-g-starch/PP-g-MA blends is evidenced. The best miscibility is however observed for low content of the ethylene-propylene copolymer-based PP-g-MA, which combines the lowest molecular weight and the highest MA-grafting level, and has a rheological behaviour (viscosity) close to that of PP-g-starch.

Regarding clay dispersion, adding a low content of ethylene-propylene copolymer-based PP-g-MA compatibilizer having a high MA-grafting level, and a polar organoclay (Cloisite ${ }^{\circledR} 30 \mathrm{~B}$ ) is the most desirable combination to optimize clay intercalation and exfoliation in PP-g-starch. Nevertheless, regarding the reinforcement effect (i.e. improvement of tensile properties), the addition of non-polar organoclay (Cloisite ${ }^{\circledR} 20 \mathrm{~A}$ ) is preferably recommended to reach higher tensile properties (modulus, yield stress, strength) without significant loss of ductility. Considering the $\mathrm{PP} /$ starch molar ratio $(1: 0.28), \mathrm{PP} /$ Cloisite ${ }^{\circledR} 20 \mathrm{~A}$ affinity is expected to promote preferential dispersion of clay within the dominant PP phase, which governs the overall mechanical behaviour in tension, whereas Cloisite ${ }^{\mathbb{R}} 30 \mathrm{~B}$ is assumed being mainly dispersed within the starch phase with less or no benefit on the tensile behaviour.

\section{Acknowledgements}

This work was carried out in the frame of the 'MATORIA' project dedicated to development of new materials from renewable resources for the automotive industry. The authors are indebted to the French Ministry of Economy, Finance and Industry, DGCIS Department, for its financial support (Contract $n^{\circ} 08290$ 6249). Thanks are also due to ROQUETTE Frères (France) for kindly supplying starchgrafted polypropylene (Gaïalene ${ }^{\circledR}$ ), to ISPA for the interfacial tension measurements, and to PSA Peugeot Citroen (France), leader of the MATORIA project, for TEM imaging. The authors also gratefully acknowledge the support and contribution of CISIT (International Campus on Safety and Intermodality in Transportation), the Nord-Pas-de-Calais Region and the European Community (FEDER, European Funds for Regional Development) for funding of the twinscrew extruder. 


\section{References}

[1] Rusu D., Boyer S. A. E., Lacrampe M-F., Krawczak P.: Bioplastics and vegetal fiber reinforced bioplastics for automotive applications. in 'Handbook of bioplastics and biocomposites engineering applications' (Ed.: Srikanth Pilla) 397-448, Wiley, New York (2011). DOI: $10.1002 / 9781118203699 . \operatorname{ch} 15$

[2] Corpart J. M.: ROQUETTE, Gaïalene ${ }^{\circledR}$. in 'International business directory for innovative bio-based plastics and composites' (eds.: Carus M., Thielen M.) 6667, Nova-Institute $\mathrm{GmbH}$ and Bioplastics Magazine, Hürth (2011).

[3] Soulestin J., Prashantha K., Lacrampe M. F., Krawczak P.: Bioplastics based nanocomposites for packaging applications. in 'Handbook of bioplastics and biocomposites engineering applications' (ed.: Srikanth Pilla), 77-120, Wiley, New York (2011).

DOI: $10.1002 / 9781118203699 . c h 4$

[4] Chen B., Evans J. R. G.: Thermoplastic starch-clay nanocomposites and their characteristics. Carbohydrate Polymers, 61, 455-463 (2005).

DOI: $10.1016 /$ j.carbpol.2005.06.020

[5] Park H-M., Li X., Jin C-Z., Park C-Y., Cho W-J., Ha C-S.: Preparation and properties of biodegradable thermoplastic starch/clay hybrids. Macromolecular Materials and Engineering, 287, 553-558 (2002).

DOI: $10.1002 / 1439-2054(20020801) 287: 8<553:: A I D-$ MAME553>3.0.CO;2-3

[6] Park H-M., Lee W-K., Park C-Y., Cho W-J., Ha C-S.: Environmentally friendly polymer hybrids. Part I: Mechanical, thermal, and barrier properties of thermoplastic starch/clay nanocomposites. Journal of Materials Science, 38, 909-915 (2003).

DOI: 10.1023/A:1022308705231

[7] Aloui M., Soulestin J., Lacrampe M-F., Krawczak P., Rousseaux D., Marchand-Brynaert J., Devaux J., Quiévy N., Sclavons M.: A new elaboration concept of polypropylene/unmodified montmorillonite nanocomposites by reactive extrusion based on direct injection of polypropylene aqueous suspensions. Polymer Engineering and Science, 49, 2276-2285 (2009).

DOI: $10.1002 /$ pen.21474

[8] Rajesh J. J., Soulestin J., Lacrampe M. F., Krawczak P.: Effect of injection molding parameters on nanofillers dispersion in masterbatch based PP-clay nanocomposites. Express Polymer Letters, 6, 237-248 (2012).

DOI: $10.3144 /$ expresspolymlett.2012.26

[9] Sharma S. K., Nema A. K., Nayak S. K.: Polypropylene nanocomposite film: A critical evaluation on the effect of nanoclay on the mechanical, thermal, and morphological behavior. Journal of Applied Polymer Science, 115, 3463-3473 (2009).

DOI: $10.1002 / a p p .30883$
[10] Dubnikova I. L., Berezina S. M., Korolev Y. M., Kim G-M., Lomakin S. M.: Morphology, deformation behavior and thermomechanical properties of polypropylene/maleic anhydride grafted polypropylene/layered silicate nanocomposites. Journal of Applied Polymer Science, 105, 3836-3850 (2007).

DOI: $10.1002 / a p p .26665$

[11] López-Quintanilla M. L., Sánchez-Valdés S., Ramos de Valle L. F., Medellín-Rodríguez F. J.: Effect of some compatibilizing agents on clay dispersion of polypropylene-clay nanocomposites. Journal of Applied Polymer Science, 100, 4748-4756 (2006).

DOI: $10.1002 / a p p .23262$

[12] López-Quintanilla M. L., Sánchez-Valdés S., Ramos de Valle L. F., Guedea Miranda R.: Preparation and mechanical properties of PP/PP-g-MA/Org-MMT nanocomposites with different MA content. Polymer Bulletin, 57, 385-393 (2006). DOI: $10.1007 / \mathrm{s} 00289-006-0555-\mathrm{x}$

[13] Svoboda P., Zeng C., Wang H., Lee L. J., Tomasko D. L.: Morphology and mechanical properties of polypropylene/organoclay nanocomposites. Journal of Applied Polymer Science, 85, 1562-1570 (2002). DOI: 10.1002/app.10789

[14] Hong C. H., Lee Y. B., Bae J. W., Jho J. Y., Nam B. U. K., Hwang T. W.: Molecular weight effect of compatibilizer on mechanical properties in polypropylene/clay nanocomposites. Journal of Industrial Engineering Chemistry, 11, 293-296 (2005).

[15] Wang Y., Chen F-B., Wu K-C.: Twin-screw extrusion compounding of polypropylene/organoclay nanocomposites modified by maleated polypropylenes. Journal of Applied Polymer Science, 93, 100-112 (2004). DOI: $10.1002 /$ app. 20407

[16] Wang Y., Chen F. B., Li Y-C., Wu K-C.: Melt processing of polypropylene/clay nanocomposites modified with maleated polypropylene compatibilizers. Composites Part B: Engineering, 35, 111-124 (2004). DOI: $10.1016 / \mathrm{S} 1359-8368(03) 00049-0$

[17] Hasegawa N., Kawasumi M., Kato M., Usuki A., Okada A.: Preparation and mechanical properties of polypropylene-clay hybrids using a maleic anhydridemodified polypropylene oligomer. Journal of Applied Polymer Science, 67, 87-92 (1998).

DOI: 10.1002/(SICI)1097-4628(19980103)67:1<87:: AID-APP10>3.3.CO;2-9

[18] Prashantha K., Soulestin J., Lacrampe M. F., Claes M., Dupin G., Krawczak P.: Multi-walled carbon nanotube filled polypropylene nanocomposites based on masterbatch route: Improvement of dispersion and mechanical properties through PP-g-MA addition. Express Polymer Letters, 2, 735-745 (2008).

DOI: $10.3144 /$ expresspolymlett.2008.87 
[19] Ray S. S., Pouliot S., Bousmina M., Utracki L. A.: Role of organically modified layered silicate as an active interfacial modifier in immiscible polystyrene/ polypropylene blends. Polymer, 45, 8403-8413 (2004). DOI: 10.1016/j.polymer.2004.10.009

[20] Ray S. S., Bousmina M.: Compatibilization efficiency of organoclay in an immiscible polycarbonate/poly (methyl methacrylate) blend. Macromolecular Rapid Communications, 26, 450-455 (2005).

DOI: $10.1002 /$ marc. 200400586

[21] Ray S. S., Bousmina M.: Effect of organic modification on the compatibilization efficiency of clay in an immiscible polymer blend. Macromolecular Rapid Communications, 26, 1639-1646 (2005).

DOI: $10.1002 /$ marc. 200500447

[22] Calcagno C. I. W., Mariani C. M., Teixeira S. R., Mauler R. S.: The role of the MMT on the morphology and mechanical properties of the PP/PET blends. Composites Science and Technology, 68, 2193-2200 (2008).

DOI: 10.1016/j.compscitech.2008.03.012

[23] Kusmono, Mohd Ishak Z. A., Chow W. S., Takeichi T., Rochmadi: Influence of SEBS-g-MA on morphology, mechanical, and thermal properties of PA6/PP/organoclay nanocomposites. European Polymer Journal, 44, 1023-1039 (2008).

DOI: $10.1016 /$ j.eurpolymj.2008.01.019

[24] Yousfi M., Soulestin J. Vergnes B., Lacrampe M-F., Krawczak P.: Compatibilization of immiscible polymer blends by organoclay: Effect of nanofiller or organo-modifier? Macromolecular Materials and Engineering, in press (2012).

DOI: $10.1002 /$ mame.201200138

[25] Owens D. K., Wendt R. C.: Estimation of the surface free energy of polymers. Journal of Applied Polymer Science, 13, 1741-1747 (1969). DOI: 10.1002/app.1969.070130815

[26] Wu S.: Formation of dispersed phase in incompatible polymer blends: Interfacial and rheological effects. Polymer Engineering and Science, 27, 335-343 (1987). DOI: $10.1002 /$ pen.760270506

[27] Wu S.: Interfacial and surface tensions of polymers melts and liquids. in 'Polymer interface and adhesion' (ed.: Wu S.) Marcel Dekker, New York, 67-132 (1982).

[28] Yu W., Li R., Zhou C.: Rheology and phase separation of polymer blends with weak dynamic asymmetry. Polymer, 52, 2693-2700 (2011). DOI: $10.1016 /$ j.polymer.2011.04.024
[29] Bai L., Li Y-M., Yang W., Yang M-B.: Rheological behavior and mechanical properties of high-density polyethylene blends with different molecular weights. Journal of Applied Polymer Science, 118, 1356-1363 (2010).

DOI: $10.1002 / a p p .32329$

[30] Schwarzl F., Staverman A. J.: Time-temperature dependence of linear viscoelastic behavior. Journal of Applied Physics, 23, 838-843 (1952).

DOI: $10.1063 / 1.1702316$

[31] Serpe G., Jarrin J., Dawans F.: Morphology-processing relationships in polyethylene-polyamide blends. Polymer Engineering and Science, 30, 553-565 (1990). DOI: 10.1002/pen.760300908

[32] Dorigato A., Pegoretti A., Penati A.: Linear low-density polyethylene/silica micro- and nanocomposites: Dynamic rheological measurements and modelling. Express Polymer Letters, 4, 115-129 (2010). DOI: $10.3144 /$ expresspolymlett.2010.16

[33] Prashantha K., Soulestin J., Lacrampe M. F., Krawczak P., Dupin G., Claes M.: Masterbatch-based multiwalled carbon nanotube filled polypropylene nanocomposites: Assessment of rheological and mechanical properties. Composites Science and Technology, 69, 1756-1763 (2009).

DOI: 10.1016/j.compscitech.2008.10.005

[34] Soulestin J., Rashmi B. J., Bourbigot S., Lacrampe MF., Krawczak P.: Mechanical and optical properties of polyamide 6/clay nanocomposite cast films: Influence of the degree of exfoliation. Macromolecular Materials and Engineering, 297, 444-454 (2012).

DOI: $10.1002 /$ mame.201100202

[35] Touchaleaume F., Soulestin J., Sclavons M., Devaux J., Cordenier F., Van Velthem P., Flat J. J., Lacrampe M. F., Krawczak P.: Efficient one-step melt-compounding of copolyetheramide/pristine clay nanocomposites using water-injection as intercalating/exfoliating aid. Express Polymer Letters, 5, 1085-1101 (2011). DOI: $10.3144 /$ expresspolymlett.2011.106

[36] Alexandre M., Dubois P.: Polymer-layered silicate nanocomposites: Preparation, properties and uses of a new class of materials. Materials Science and Engineering R: Reports, 28, 1-63 (2000). DOI: $10.1016 / \mathrm{S} 0927-796 \mathrm{X}(00) 00012-7$ 